\title{
Impact of Homocysteine and Calcium Score Levels on the Risk Assessment of Percutaneous Transluminal Coronary Angioplasty (PTCA) Undergone patients
}

\author{
R. DHANYA AND ANOOJA THOMAS
}

See end of the paper for authors' affiliation

Correspondence to :

R. DHANYA

Department of Home Science, St. Teresa's College, ERNAKULAM (KERALA) INDIA

\section{KEY WORDS :}

Coronary artery disease, PTCA, Biomarkers, Homocysteine, C-reactice protein, Calcium scores
ABSTRACT : Cardio-vascular disease is increasing its pace day by day and is the leading cause of mortality and morbidity. Though the traditional biomarkers are made available, the novel biomarkers are been incorporated to predict the risk of cardio-vascular diseases for early detection. The present study aimed to investigate the impact of C-reactive protein and calcium score levels in the risk assessment of percutaneous transluminal coronary patients. Four hundred cardio-vascular patients selectively males were randomly selected from Visakhapatnam district Andhrapradesh. Information on economic background, anthropometric measurements, diet history, life style habit and medical history of the subjects were collected using an interview schedule. All the subjects were screened to know they are on medical management or on surgical management. Data collected were consolidated and tabulated. Among the four hundred subjects 220 subjects were found to undergo PTCA. From this group a sub sample of 50 patients were selected and analyzed for their lipid profile, C-reactive protein, serum albumin, homocystiene and calcium score levels before and after PTCA. Statistical analysis was done and interpreted. Even though a wide variety of biomarkers were available for assessing the risk of coronary artery disease subjects, C-reactive protein and calcium score levels were found to be the most significant biomarkers to predict the risk of cardio-vascular diseases. The present study identified these two parameters as the most predictive biomarkers among the usual clinical investigations conducted for the clinicians to predict the severeness of the cardio-vascular disease and to correct the scenario with PTCA.

How to cite this paper : Dhanya, R. and Thomas, Anooja (2017). Impact of Homocysteine and Calcium Score Levels on the Risk Assessment of Percutaneous Transluminal Coronary Angioplasty (PTCA) Undergone patients. Internat. J. Med. Sci., 10(1\&2) : 1-6, DOI : 10.15740/HAS/IJMS/10.1and2/1-6. 